\title{
Sirtuin 1 Levels in Recurrent Implantation Failure
}

\section{Níveis de sirtuína 1 em falhas recorrentes de implantação}

\author{
Yaprak Engin-Ustun ${ }^{1} \quad$ A. Seval Ozgu-Erdinc ${ }^{1} \quad$ Emel Kiyak Caglayan $^{1} \quad$ Cavidan Gulerman ${ }^{1}$ \\ Esma Sarikaya ${ }^{1}$ Ayla Aktulay ${ }^{1}$ Canan Demirtas ${ }^{2}$ Salim Erkaya ${ }^{1}$ Nafiye Yilmaz ${ }^{1}$
}

${ }^{1}$ Reproductive Endocrinology Department, University of Health Sciences, Dr. Zekai Tahir Burak Health Practice Research Center, Ankara, Turkey

2 Biochemistry Department, Gazi University, Ankara, Turkey

Rev Bras Ginecol Obstet 2017;39:541-544.

\author{
Address for correspondence A. Seval Ozgu-Erdinc, University of \\ Health Sciences, Dr. Zekai Tahir Burak Health Practice Research \\ Center, Ankara, Turkey (e-mail: sevalerdinc@gmail.com).
}

\begin{abstract}
Keywords

- recurrent implantation failure

- sirtuin

- pregnancy

- in vitro fertilization

\section{Resumo}

\section{Palavras-chave}

- falhas recorrentes de inseminação

- sirtuína

- gravidez

- fertilização in vitro

Sirtuin 1 has an important role in cellular processes, including apoptosis and cellular stress. The purpose of this study was to assess serum sirtuin 1 levels in women with recurrent implantation failure (RIF). In this cross-sectional study, we included 28 women with RIF, 29 healthy women who had conceived by in vitro fertilization (IVF), and 30 women with a 1-cycle failure of IVF as controls. Human serum nicotinamide adenine dinucleotide (NAD)-dependent deacetylase sirtuin-1 (SIRT1/SIRT2L1) levels were detected using a commercial colorimetric kit. Recurrent implantation failure patients have higher sirtuin 1 levels than non-pregnant women and healthy pregnant women, but this difference did not reach statistical significance due to the low number of patients in our study. These higher sirtuin 1 levels may result from the inflammation imbalance of RIF patients. The only statistically significant correlation found was between age and sirtuin $(r=0.277, p=0.009)$.

A sirtuína 1 tem importante função nos processos celulares, incluindo a apoptose e o estresse celular. $O$ objetivo deste estudo é o de avaliar níveis de sirtuína 1 em mulheres com falhas recorrentes de implantação (FRI). Neste estudo cruzado, incluímos 28 mulheres com FRI, 29 mulheres saudáveis que deram à luz por fertilização in vitro (FIV) bem-sucedida, e 30 mulheres com 1 ciclo de FIV malsucedido como controle. Os níveis de sirtuína 1 em soro humano de desacetilase dependente de dinucleotídeo de nicotinamida adenina (DNA) (SIRT1/SIRT2L1) foram detectados usando um kit colorimétrico comercial. Pacientes com FRI tiveram níveis de sirtuína 1 superiores às pacientes grávidas e aos controles, mas esta diferença não atingiu significância estatística devido ao baixo número de pacientes envolvidos. Estes níveis mais altos de sirtuína 1 podem ser resultado da inflamação desigual em pacientes com FRI. A única correlação estatisticamente significante encontrada foi entre idade e sirtuína $(r=0,277, p=0,009)$.
\end{abstract}

received

February 13, 2017

accepted

August 3, 2017

published online

September 1, 2017
DOI https://doi.org/

10.1055/s-0037-1606349.

ISSN 0100-7203.
Copyright $\odot 2017$ by Thieme Revinter

Publicações Ltda, Rio de Janeiro, Brazil
License terms

(요 (1) $\Theta \circledast$ 


\section{Introduction}

Successful implantation requires reciprocal interaction between the blastocyst and the endometrium. The maternal immune system has a role in this interaction, as well as the mediators secreted from the endometrium. The receptivity of the endometrium is crucial for processes of implantation and placentation. The evidence of implantation may be observed with an ultrasound examination. Recurrent implantation failure (RIF) is an important problem in in vitro fertilization (IVF)/intracytoplasmic sperm injection (ICSI) cycles. ${ }^{1,2}$ Along with different definitions, RIF is defined as implantation that has repeatedly failed to achieve a clinical pregnancy after a cumulative transfer of more than 3 good-quality embryos in at least 3 fresh or frozen unsuccessful cycles in a woman under the age of 40 years. $^{3}$ Decrease in endometrial receptivity, uterine factors, embryonic defects, immunological factors, factors associated with thrombophilia, and other combined factors can be defined in RIF etiology. ${ }^{2,4}$ The balance state of pro- and anti-inflammatory cytokines is crucial for implantation and to maintain the pregnancy. ${ }^{5}$ Pro-inflammatory cytokines are increased in $\mathrm{RIF}^{3}$

Sirtuin 1, also known as nicotinamide adenine dinucleotide (NAD)-dependent class III protein deacetylase, ${ }^{6}$ plays an important role in cellular processes, including gene expression, cell cycle regulation, cell metabolism, oxidative stress response, apoptosis, cellular stress, DNA repair and aging. ${ }^{7-9}$ Sirtuin 1 also has effects in chronic inflammation and immune response. ${ }^{10,11}$ The aim of this study is to define the effect of sirtuin 1 levels in RIF patients.

\section{Methods}

This cross-sectional study sample consisted of 87 women. The study was conducted according to the Declaration of Helsinki. ${ }^{12}$ The institutional review board (\# 26/6/2014) approved the study. The RIF group included 28 infertile women. Recurrent implantation failure was defined as failure to achieve a clinical pregnancy after a cumulative transfer of at least 3 good-quality embryos in at least 3 fresh or frozen unsuccessful cycles in a woman under the age of 40 years. The two control groups included 29 healthy women who had conceived by in vitro fertilization (IVF), and 30 women with a 1-cycle failure of IVF. Age, body mass index (BMI), antral follicle count (AFC), estradiol, follicle-stimulating hormone (FSH), luteinizing hormone (LH), prolactin and thyroidstimulating hormone (TSH) levels were evaluated. Blood samples were obtained in the morning from the 1st to 3rd days of the menstrual cycle, following at least 8 hours of fasting. Centrifugation of the samples was performed at 3,000 rpm for 10 minutes, and the supernatant serum was separated and stored at $-80^{\circ} \mathrm{C}$ until the assays were performed. The BMI was calculated in all of the patients and controls as $\mathrm{kg} / \mathrm{m}^{2}$. Commercial colorimetric enzyme-linked immunosorbent assay (ELISA) kits (Hangzhou Eastbiopharm, Hangzhou, China) were used for the measurement of human serum NAD-dependent deacetylase sirtuin-1 (SIRT1/SIRT2L1) using appropriate wavelengths and a microplate reader (EL X 800 TM, BioTek Instruments, Winooski, Vermont, US), according to the manufacturer's instructions. The concentrations were calculated over the standard curves. The intra-assay precision was CV (Coefficients of Variability) $\%<8 \%$, and the inter-assay precision was $\mathrm{CV} \%<10 \%$. The assay range was $0.2-$ $60 \mathrm{ng} / \mathrm{mL}$, and the sensitivity of the assay was $0.09 \mathrm{ng} / \mathrm{mL}$. The kit uses a double-antibody sandwich ELISA. The results were expressed as $\mathrm{ng} / \mathrm{mL}$ of protein. Complete blood count, and fasting plasma glucose (FPG), FSH, LH, estradiol, prolactin and TSH levels were evaluated in all participants.

We tested the normality of the distribution of the variables using the Kolmogorov-Smirnov and Shapiro-Wilk tests. When the normality tests revealed normal distribution, one-way analysis of variance (ANOVA) was used followed by Bonferroni to compare the differences between two groups. When the test failed, comparisons of variables among the groups were performed using the Kruskal-Wallis non-parametric analysis of the variance, followed by Mann-Whitney $U$ tests for pairwise comparisons. Demographic variables and test results were presented as mean with standard deviation (SD), or median with range for continuous variables. Pearson correlation coefficients were calculated for continuous variables with normal distribution, and Spearman rank correlation coefficients were calculated for non-normally distributed continuous variables. A two-tailed $p$-value $<0.05$ was considered statistically significant. The Statistical Package for the Social Sciences (SPSS, IBM Corp., Armonk, NY, US), version 23.0, was used for the data analyses.

\section{Results}

There were no significant differences in terms of age, BMI, AFC, estradiol, FSH, LH, TSH and prolactin levels among the three groups (-Table 1). There were no significant differences in terms of hematological inflammatory parameters, white blood cells (WBCs), neutrophils, lymphocytes, mean platelet volume (MPV), platelet distribution width (PDW), and systemic inflammatory response (SIR) markers, such as the neutrophil/lymphocyte ratio (NLR) and the platelet/ lymphocyte ratio (PLR) among the three groups ( - Table $\mathbf{1}$ ). Recurrent implantation failure patients have higher sirtuin 1 levels than non-pregnant women and healthy pregnant women, but this difference did not reach statistical significance in the present study (-Table1). We found no correlation between any of the variables and sirtuin. The only statistically significant correlation found was between age and $\operatorname{sirtuin}(\mathrm{r}=0.277, p=0.009)$.

\section{Discussion}

This is the first study investigating the association between sirtuin 1 and RIF. We found that the study groups did not differ in terms of the level of serum sirtuin 1 . The process of implantation depends on different factors, such as the quality of the embryo, optimal culture conditions, the receptivity of the endometrium, and the maternal immune system. ${ }^{13}$ According to data from studies performed with RIF patients, proinflammatory cytokines are increased, while anti-inflammatory cytokines are decreased, ${ }^{3}$ and abnormal cytokine 
Table 1 Characteristics of the three groups

\begin{tabular}{|c|c|c|c|c|}
\hline & $\begin{array}{l}\text { Non-pregnant } \\
(n=30)\end{array}$ & $\begin{array}{l}\text { Pregnant } \\
(n=29)\end{array}$ & $\begin{array}{l}\text { RIF } \\
(n=28)\end{array}$ & $p$ \\
\hline Age (years) & $30.3 \pm 5.1$ & $31.1 \pm 5.0$ & $30.9 \pm 4.9$ & 0.811 \\
\hline BMI $\left(\mathrm{kg} / \mathrm{m}^{2}\right)$ & $24.5 \pm 4.6$ & $25.8 \pm 4.2$ & $25.5 \pm 4.5$ & 0.341 \\
\hline Estradiol $(\mathrm{pg} / \mathrm{mL})$ & $42.5 \pm 16.4$ & $42.4 \pm 13.1$ & $36.2 \pm 13.2$ & 0.264 \\
\hline $\mathrm{FSH}(\mathrm{mlU} / \mathrm{mL})$ & $6.9 \pm 2.3$ & $8.5 \pm 4.1$ & $7.7 \pm 4.7$ & 0.348 \\
\hline $\mathrm{LH}(\mathrm{mlU} / \mathrm{mL})$ & $4.4(1.5-11.7)$ & $4.7(0.9-28.4)$ & $3.9(1.8-19.4)$ & 0.854 \\
\hline Prolactin $(\mathrm{ng} / \mathrm{mL})$ & $14(1.2-29.7)$ & $11.9(0.6-53.8)$ & $12.7(5.5-32.2)$ & 0.508 \\
\hline $\mathrm{TSH}(\mathrm{mlU} / \mathrm{mL})$ & $2(0.3-9.4)$ & $1.6(0.4-6.1)$ & $1.9(0.4-5)$ & 0.154 \\
\hline $\operatorname{AFC}(n)$ & $11.5(4-22)$ & $14(2-22)$ & $12(7-22)$ & 0.512 \\
\hline WBCs $\left(\times 10^{3} / \mu \mathrm{L}\right)$ & $7.4 \pm 1.7$ & $7.1 \pm 1.6$ & $7.2 \pm 1.3$ & 0.789 \\
\hline Neutrophils $\left(\times 10^{3} / \mu \mathrm{L}\right)$ & $4.7 \pm 1.3$ & $4.4 \pm 1.4$ & $4.4 \pm 1.1$ & 0.555 \\
\hline Lymphocytes $\left(\times 10^{3} / \mu \mathrm{L}\right)$ & $2.2 \pm 0.6$ & $2.1 \pm 0.6$ & $2 \pm 0.6$ & 0.629 \\
\hline MPV (fl) & $16.1(2.9-10.7)$ & $16.1(15.3-17.1)$ & $15.9(11.2-16.5)$ & 0.368 \\
\hline PDW & $9.9(7.9-13.1)$ & $9.5(7.2-13.1)$ & $9.8(7.7-12.3)$ & 0.121 \\
\hline NLR & $2(1.1-4.7)$ & $2.1(0.7-4.3)$ & $2(1.3-7.2)$ & 0.993 \\
\hline PLR & $130(68.4-301.5)$ & $137.6(81.9-304.9)$ & $142.1(84.9-1160)$ & 0.420 \\
\hline Sirtuin $(\mathrm{ng} / \mathrm{mL})$ & $6.3(2.2-37.1)$ & $6.5(2.8-26.3)$ & $7.4(2.7-36.0)$ & 0.318 \\
\hline
\end{tabular}

Abbreviations: AFC, antral follicle count; BMI, body mass index; FSH, follicle-stimulating hormone; LH, luteinizing hormone; MPV, mean platelet volume; NLR, neutrophil/lymphocyte ratio; PDW, platelet distribution width; PLR, platelet/lymphocyte ratio; RIF, recurrent implantation failure; TSH, thyroid-stimulating hormone (TSH); WBCs, white blood cells.

production causes RIF. ${ }^{14,15}$ It is not the only factor in fetal and maternal unit hemostasis. These complex interactions change as the pregnancy progresses. The interactions between the fetal and maternal unit changes with the progression of pregnancy. ${ }^{16}$ Moreover, apoptosis plays an important role in the progression of pregnancy. ${ }^{17}$

Sirtuin 1 reduces the apoptosis induced by DNA damage and oxidative stress. Shirane et $\mathrm{al}^{18}$ revealed that the activation and increased expression of SIRT1 play an important role in uterine receptivity. Additionally, sirtuin 1 inhibits inflammatory pathways through macrophages, and is also effective in metabolic syndrome. ${ }^{10}$ In an another study, mitochondrial dysfunction, oxidative stress and inflammation states were found associated with a decrease in sirtuin 1 levels in joint tissue. ${ }^{19}$ Conti et $\mathrm{al}^{20}$ concluded that inflammation and oxidative stress in chronic obstructive pulmonary disease is related to an increase in sirtuin 1 levels.

According to a study by Van Gool et $\mathrm{al}^{21}$ in animals, sirtuin inhibits nicotinamide phosphoribosyl transferase and, after that, it reduces NAD levels, resulting in a decrease in the levels of tumor necrosis factor (TNF), interferon gamma (IFNY), and in the amount of lymphocytes in the peripheral blood. Kong et a ${ }^{22}$ also indicated that the activation of sirtuin 1 had a potential therapeutic function in autoimmune inflammatory diseases. On the other hand, Lugrin et $\mathrm{al}^{23}$ expressed that the inhibition of sirtuin by pharmacological agents results in treatment of the acute and chronic inflammatory responses.

As a conclusion of this study, RIF patients have higher sirtuin 1 levels than non-pregnant women and healthy pregnant women, but this difference did not reach statistical significance due to the low number of patients in our study. This higher sirtuin 1 levels may result from the inflammation imbalance of RIF patients. Therefore, further studies with large samples are needed.

\section{Conflicts of Interest}

Authors declare no conflicts of interest.

\section{References}

1 Simon A, Laufer N. Assessment and treatment of repeated implantation failure (RIF). J Assist Reprod Genet 2012;29(11):1227-1239

2 Margalioth EJ, Ben-Chetrit A, Gal M, Eldar-Geva T. Investigation and treatment of repeated implantation failure following IVF-ET. Hum Reprod 2006;21(12):3036-3043

3 Liang PY, Diao LH, Huang CY, et al. The pro-inflammatory and anti-inflammatory cytokine profile in peripheral blood of women with recurrent implantation failure. Reprod Biomed Online 2015; 31(06):823-826

4 Hekimoğlu R, Pergin A, Uğur Y, Beksaç S, Turğal M, Çakar N. Impaired implantation and hereditary thrombophila; expression of LIF (Leukemia Inhibitory Factor) on extravillous trophoblasts. Gynecol Obstet Reprod Med. 2012;18:123-126

5 Orsi NM, Tribe RM. Cytokine networks and the regulation of uterine function in pregnancy and parturition. J Neuroendocrinol 2008;20(04):462-469

6 Haigis MC, Guarente LP. Mammalian sirtuins-emerging roles in physiology, aging, and calorie restriction. Genes Dev 2006;20 (21):2913-2921

7 Rodgers JT, Puigserver P. Fasting-dependent glucose and lipid metabolic response through hepatic sirtuin 1. Proc Natl Acad Sci U S A 2007;104(31):12861-12866

8 Zhang J, Fang L, Lu Z, et al. Are sirtuins markers of ovarian aging? Gene 2016;575(2 Pt 3):680-686 
9 Nogueiras R, Habegger KM, Chaudhary N, et al. Sirtuin 1 and sirtuin 3: physiological modulators of metabolism. Physiol Rev 2012;92(03):1479-1514

10 Schug TT, Xu Q, Gao H, et al. Myeloid deletion of SIRT1 induces inflammatory signaling in response to environmental stress. Mol Cell Biol 2010;30(19):4712-4721

11 Kiyak Caglayan E, Engin-Ustun Y, Gocmen AY, Polat MF, Aktulay A. Serum sirtuin 1 levels in patients with polycystic ovary syndrome. J Obstet Gynaecol 2015;35(06):608-611

12 World Medical Association. World Medical Association Declaration of Helsinki: ethical principles for medical research involving human subjects. JAMA 2013;310(20):2191-2194

13 Luz CM, Giorgi VS, Coelho Neto MA, Martins WP, Ferriani RA, Navarro PA. Association between number of formed embryos, embryo morphology and clinical pregnancy rate after intracytoplasmic sperm injection. Rev Bras Ginecol Obstet 2016;38(09):465-470

14 Laird SM, Tuckerman EM, Li TC. Cytokine expression in the endometrium of women with implantation failure and recurrent miscarriage. Reprod Biomed Online 2006;13(01):13-23

15 Fukui A, Funamizu A, Yokota M, et al. Uterine and circulating natural killer cells and their roles in women with recurrent pregnancy loss, implantation failure and preeclampsia. J Reprod Immunol 2011;90(01):105-110
16 Saini V, Arora S, Yadav A, Bhattacharjee J. Cytokines in recurrent pregnancy loss. Clin Chim Acta 2011;412(9-10):702-708

17 Boeddeker SJ, Hess AP. The role of apoptosis in human embryo implantation. J Reprod Immunol 2015;108:114-122

18 Shirane A, Wada-Hiraike O, Tanikawa M, et al. Regulation of SIRT1 determines initial step of endometrial receptivity by controlling E-cadherin expression. Biochem Biophys Res Commun 2012;424 (03):604-610

19 Liu-Bryan R. Inflammation and intracellular metabolism: new targets in OA. Osteoarthritis Cartilage 2015;23(11):1835-1842

20 Conti V, Corbi G, Manzo V, Pelaia G, Filippelli A, Vatrella A. Sirtuin 1 and aging theory for chronic obstructive pulmonary disease. Anal Cell Pathol (Amst) 2015;2015:897327

21 Van Gool F, Gallí M, Gueydan C, et al. Intracellular NAD levels regulate tumor necrosis factor protein synthesis in a sirtuindependent manner. Nat Med 2009;15(02):206-210

22 Kong S, Yeung P, Fang D. The class III histone deacetylase sirtuin 1 in immune suppression and its therapeutic potential in rheumatoid arthritis. J Genet Genomics 2013;40(07):347-354

23 Lugrin J, Ciarlo E, Santos A, et al. The sirtuin inhibitor cambinol impairs MAPK signaling, inhibits inflammatory and innate immune responses and protects from septic shock. Biochim Biophys Acta 2013;1833(06):1498-1510 